\title{
On the frequency distribution of net annual snow accumulation at the South Pole
}

\author{
C. J. van der Veen \\ Byrd Polar Research Center, The Ohio State University, Columbus OH 43210
}

\section{M. Whillans}

Byrd Polar Research Center and Department of Geological Sciences, The Ohio State University, Columbus OH 43210

\author{
A. J. Gow \\ U.S. Army Cold Regions Research and Engineering Laboratory, 72 Lyme Road, Hanover NH 03755
}

\begin{abstract}
The frequency distribution of stratigraphic layer thickness in cores and a snowmine at South Pole is not compatible with a significant number $(>1 \%)$ of missing layers associated with zero-accumulation years inferred from poleheight measurements. A reconciliation of these data sets is needed if observed stratigraphic records are to be used as reliable paleoclimate indicators. Three explanations for the discrepancy are offered, namely (i) during a significant number of years, a visible stratigraphic horizon does not form or is not identified, (ii) the true distribution is characterized by two maxima, with a secondary maximum centered around zero layer thickness, or (iii) the pole-height measurements are misinterpreted and there are very few zero-accumulation years at South Pole. With the currently available data, it is not possible to discriminate among these three possibilities.
\end{abstract}

\section{Introduction}

An important impediment to establishing accurate annual chronologies in ice cores is the possibility that some annual layers may be missing from the stratigraphic record. The formation of annual units in the stratigraphy is due to certain snow characteristics varying according to the time of year. Whichever dating method is used, the assumption is that some clearly identifiable stratum exists that marks individual years. However, some annual layers and their corresponding markers may be missing as a result of wind scour and erosion, or because of lack of accumulation [Gow, 1965]. The effect of such a hiatus in the record is an underestimation of the age of deeper layers. Where annual layers are used to estimate the accumulation rate, missing layers result in a long-term average accumulation rate that is too large.

Although the average layer thickness is dependent on the fraction of missing layers, the thickness of an individual layer is not affected by missing layers. This means that core records can be used to investigate the frequency distribution of annual layer thickness or, equivalently, net annual deposition, even if there are missing layers. Furthermore, it may be possible to use the measured frequency distribution to infer the probability of missing layers by extrapolating the distribution to small layer thicknesses.

Copyright 1999 by the American Geophysical Union.

Paper number 1998GL900271. 0094-8276/99/1998GL900271\$05.00
A particular motivation for the present study is the frequency analysis of 2027 annual snow accumulation layers identified in a $202.4 \mathrm{~m}$ core obtained during the austral summer 1981-82 near South Pole and dated using visible stratigraphy [Hogan and Gow, 1997]. This observed record is used to discuss the importance of missing layers and whether its frequency distribution is compatible with other estimates for the number of missing years, and whether the frequency distribution observed in a single core accurately reflects the true frequency distribution of net accumulation at South Pole.

\section{Observed Frequency Distribution}

The observed distribution of annual layer thickness in the $202.4 \mathrm{~m}$ core is shown in the upper panel of Figure 1, using equal size ( $5 \mathrm{~mm}$ water equivalent) binning intervals. The vertical dashed line represents the sample mean $(75 \mathrm{~mm}$ w.e.). The standard deviation of the observed record is $28 \mathrm{~mm}$ w.e. The important features of the distribution are its asymmetry, or skewness, and the smooth approach to zero as the layer thickness decreases to zero. Because of the skewness, the peak in the distribution is displaced towards smaller values relative to the mean.

According to Hogan and Gow [1997], the observed distribution is best described as log-normal, with the logarithm of layer thickness normally (or Gaussian) distributed. This distribution is very similar to the gamma distribution, commonly used in meteorology to describe for example the frequency distribution of rainfall and considered in this study. McConnell et al. [1997] also use gamma distributions to model monthly snow accumulation at South Pole. If $x$ represents the layer thickness (in $\mathrm{mm}$ w.e.) the probability density function (pdf) is given by [Thom, 1958]

$$
G(x)=\frac{\lambda^{r}}{\Gamma(r)} x^{r-1} e^{-\lambda x}, \quad(x \geq 0),
$$

with

$$
\Gamma(r)=\int_{0}^{\infty} y^{r-1} e^{-y} d y, \quad(r>0),
$$

the gamma function of $r$. The two parameters, $r$ and $\lambda$, must be positive and are related to the sample mean and variance 


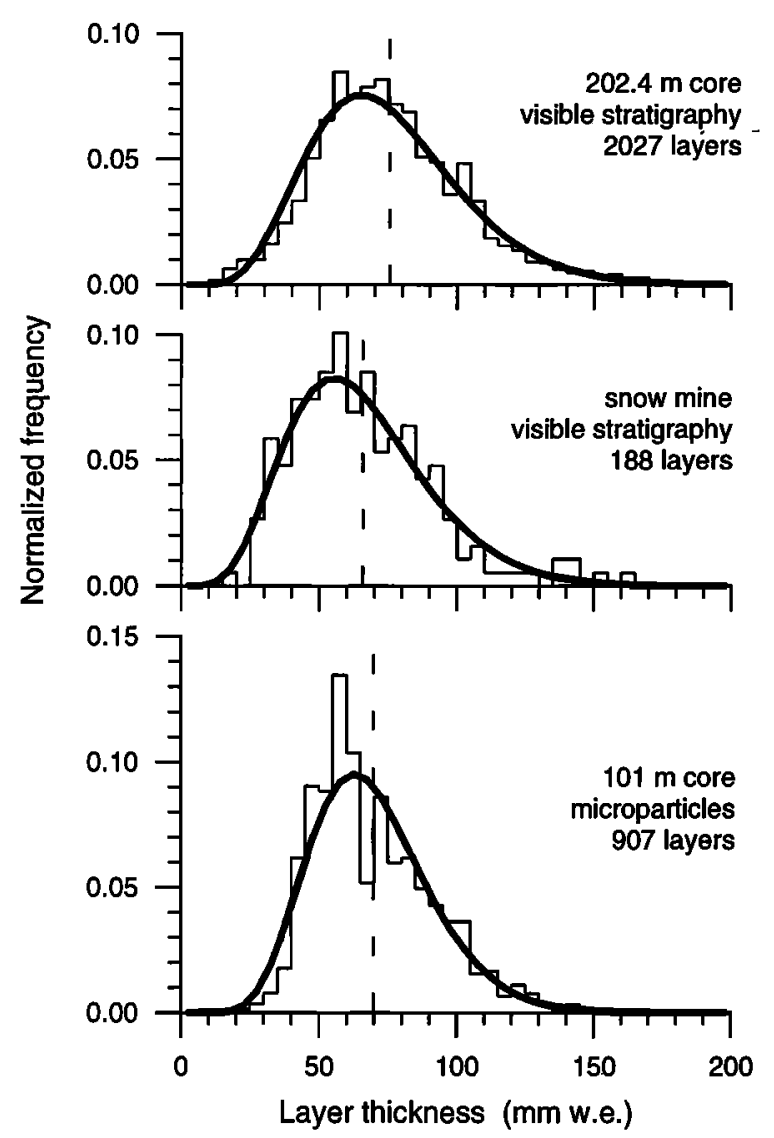

Figure 1. Three measured histograms of annual layer thickness, and fitted gamma probability distributions (heavy curves). Vertical dashed lines represent the long-term average layer thickness.

through $\bar{x}=r / \lambda$ and $\sigma_{x}^{2}=r / \lambda^{2}$. The peak or maximum in the distribution occurs at $x_{p}=(r-1) / \lambda$ [e.g. Casella and Berger, 1990, p. 100-101]. This distribution is represented by the heavy curve in Figure 1.

Two other measured records of accumulation rate at South Pole yield very similar distributions (Figure 1). The distribution shown in the middle panel is based on visible stratigraphy of 188 snow layers in a snow mine near South Pole [Giovinetto and Schwerdtfeger, 1966]. The snow-mine stratigraphy is considered more representative because annual strata were traced on longer sections of the exposed walls (as opposed to $\sim 0.1 \mathrm{~m}$ core diameter). The distribution shown in the lower panel is based on a $101 \mathrm{~m}$ core retrieved in 1974 about $370 \mathrm{~m}$ from the site of the $202.4 \mathrm{~m}$ core, and analyzed continuously for microparticle concentration [MosleyThompson and Thompson, 1982]. Successive accumulation years can be identified by peaks in microparticle concentration. Because of the relatively large sample size (16 - 18 $\mathrm{mm}$ ), thin layers are not detectable by this method. The frequency distribution of these two records also exhibit the characteristics of the gamma distribution.

\section{Frequency Distribution and Missing Layers}

The gamma pdf cannot be a realistic description of actual variations in annual snow accumulation if there is a significant number of zero-accumulation years. As defined above, the predicted probability of a zero-accumulation year is zero. Measurements of exposed pole heights indicate that as many as $\sim 5 \%$ years may be missing because of zero or negative net accumulation [Mosley-Thompson et al., 1995].

One possibility to arrive at a probability distribution that describes the data and allows for zero-thickness layers, is to apply a transformation to the gamma pdf. For the present case of a bounded pdf, a useful transformation is accomplished by adding a location parameter, $\varepsilon$, to the layer thickness [Haan, 1977, p. 123]. This preserves the gross shape of the distribution but includes a finite number of zero-thickness layers. The transformed pdf is

$$
\widetilde{G}(x)=\frac{\lambda^{r}}{\Gamma(r)}(x+\varepsilon)^{r-1} e^{-\lambda(x+\varepsilon)}, \quad(x>-\varepsilon) .
$$

The three parameters, $r, \lambda$, and $\varepsilon$, are related to the average value, $\bar{x}$, the peak value, $x_{p}$, and the standard deviation, $\sigma_{x}$, through $\bar{x}=r / \lambda-\varepsilon, x_{p}=(r-1) / \lambda-\varepsilon$, and $\sigma_{x}^{2}=r / \lambda^{2^{2}}$. Adopting a value of $5 \%$ for the number of zero-thickness layers provides an additional constraint.

Some of the possible distribution functions are shown in Figure 2; values of parameters used are given in Table 1. Even without conducting formal statistical tests, it is clear that the measured distribution is incompatible with a significant $(>$ $1 \%)$ number of missing layers and the gamma distribution.

There are several possible explanations for the discrepancy, and these are discussed and evaluated below. It may be noted that transforming other distribution functions (lognormal, Gaussian) does not alleviate the problem and yields essentially the same discrepancy.

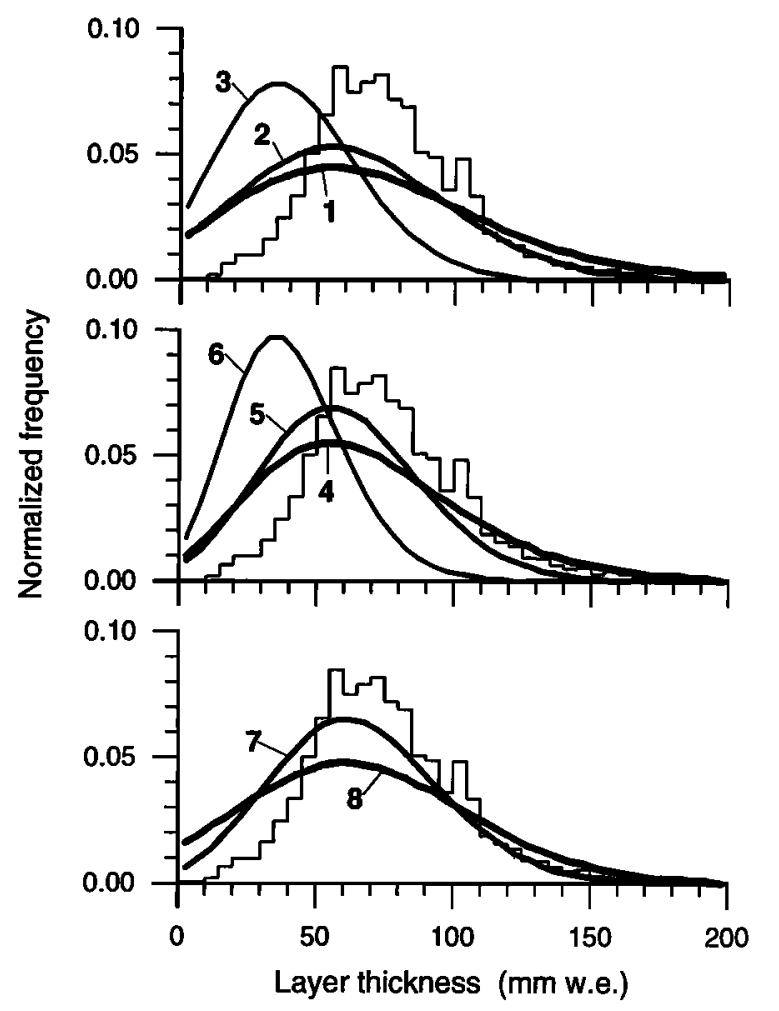

Figure 2. Observed layer thickness distribution in the 202.4 $\mathrm{m}$ core and transformed gamma distributions (numbered curves). Parameter values for the distributions are given in Table 1. 
Table 1. Parameter Values for the Distribution Functions Shown in Figure 2.

\begin{tabular}{lcccccccc}
\hline & \multicolumn{10}{c}{ CURVE } \\
& 1 & 2 & 3 & 4 & 5 & 6 & 7 & 8 \\
\hline $\mathrm{x}_{\mathrm{p}}$ (mm w.e.) & 55.0 & 55.0 & 35.0 & 55.0 & 55.0 & 35.0 & 61.0 & 61.0 \\
$\overline{\mathrm{x}}$ (mm w.e.) & 67.9 & 60.0 & 40.0 & 67.9 & 60.0 & 40.0 & 66.0 & 66.0 \\
$\sigma_{\mathrm{X}}$ (mm w.e.) & 46.0 & 38.0 & 26.0 & 38.0 & 29.0 & 21.0 & 31.0 & 42.0 \\
$\begin{array}{c}\text { zero-thickness } \\
\text { layers (\%) }\end{array}$ & 4.9 & 4.9 & 4.9 & 1.2 & 1.0 & 1.3 & 0.9 & 5.0 \\
$\begin{array}{c}\text { number of missed } \\
\text { years }\end{array}$ & 192 & 482 & 1736 & 209 & 503 & 1764 & 274 & 251 \\
\hline
\end{tabular}

\section{Are the Stratigraphic Observations Reliable?}

One possibility is that the measured frequency distribution is not representative of the true distribution. Very thin layers are not detectable by visible stratigraphy and the observed frequency distribution will have no values that approach zero layer thickness. It could also be that some annual horizons are not identified because a distinctive depth hoar layer does not form every year, or not all annual horizons are well preserved or clearly visible. In some years, the distinctive depth hoar layer may be replaced by a coarse-grained equivalent (summer-coarsened snow) overlain by fine-grained snow of the ensuing fall or winter [Gow, 1965]. Failure to identify all annual layer markers would bias the frequency distribution towards thicker layers.

A number of studies has been conducted to assess the validity of visible stratigraphy as a dating method. Most of these apply to short time intervals $(\sim 5 \mathrm{yr})$ or regions where annual accumulation is significantly larger than at South Pole. The study of Jouzel et al. [1983] applies to South Pole and considers longer periods $(80-300 \mathrm{yr})$. Their conclusion is that visible stratigraphy is a reliable method for dating ice cores.

Jouzel et al. [1983] compared a continuous and detailed deuterium profile measured in South Pole firn samples extending back to $1887 \mathrm{AD}$ with visible stratigraphic summer horizons dating back to 1926/27. For the period 1927-1978, there is excellent agreement between maxima in deuterium concentration and summer horizons, although some of the deuterium peaks are less obvious. This suggests that annual horizons are formed every year and preserved in the stratigraphic record, except during zero-accumulation years (which cannot be detected by either dating method). Absolute dating of the latter part of the observed record was provided by elevated levels of $\beta$-activity in the 1955 stratum, associated with radioactive debris from the Castle series tests. This reference level agrees with the stratigraphic dating and demonstrates that between 1955 and 1978 a visible stratigraphic horizon formed each year. Because of the short time period considered ( $23 \mathrm{yr}$ ), this test is not conclusive.

For any given year there are two possibilities, namely a layer is identified or it is not recognized in the record. The assumption is made that identification of annual layers is statistically independent. The probability that a layer is not identified is denoted by $\mathrm{Q}$. In a sample of $\mathrm{N}$ measurements, the expected number of missing horizons is then NQ while the expected number of identified horizons is $\mathrm{N}(1-\mathrm{Q})$. To evaluate the range of values for $Q$ compatible with the observations of Jouzel et al. [1983] Pearson's C can be used.
Let $\mathrm{X}^{+}$and $\mathrm{X}^{-}=\mathrm{N}-\mathrm{X}^{+}$represent the number of recognized and missed layers, respectively. Adopting a $95 \%$ significance level, the pro' ' 'bility $Q$ can be determined from the requirement that

$$
\mathrm{C}=\frac{\left(\mathrm{X}^{+}-\mathrm{N}(1-\mathrm{Q})\right)^{2}}{\mathrm{~N}(1-\mathrm{Q})}+\frac{\left(\mathrm{X}^{-}-\mathrm{NQ}\right)^{2}}{\mathrm{NQ}} \leq \chi_{0.95,1}^{2}=3.841,
$$

[e.g. Larsen and Marx, 1986, p. 402-403]. In the 23 year period considered by Jouzel and others (1983), there are no layers missing, and $\mathrm{N}=23, \mathrm{X}^{+}=23$ and $\mathrm{X}^{-}=0$. Adopting a $95 \%$ confidence level, the probability $Q$ must be less than $14 \%$. In other words, the comparative study of Jouzel et al. [1983] indicates that up to $14 \%$ of annual stratigraphic horizons may be missing. For the 2027 year core record, this correponds to a maximum of 283 missed annual markers.

The lower panel in Figure 2 shows two distribution functions whose average corresponds to 0.9 and $5 \%$ missing annual markers, in addition to 1 and $5 \%$ zero-accumulation years. For both distributions, the average layer thickness is $66 \mathrm{~mm}$ w.e., compared to $75 \mathrm{~mm}$ r.e. inferred from the 202.4 $\mathrm{m}$ core. The smaller value agrees with the average from the snow mine ( $65 \mathrm{~mm}$ w.e.) and is somewhat less than the average determined from microparticle analysis ( $70 \mathrm{~mm}$ w.e.).

\section{Are There Zero-Accumulation Years?}

A second possibility is that the interpretation of stake measurements can be challenged and that the number of zeroaccumulation years is considerably less than 5\%. MosleyThompson et al. [1995] considered a six year record of annual accumulation along a 42 pole pentagon established in January, 1958, near South Pole [Giovinetto and Schwerdtfeger, 1966]. Of the 42 poles, 35 have an uninterrupted record, for a total of 210 accumulation measurements. Zero or negative accumulation was recorded nine times and Mosley-Thompson et al. [1995] interpret this as indicating a $4.3 \%$ probability for a hiatus year to occur.

Almost half of the negative accumulations were observed during the first measurement year (November, 1958 - November, 1959). For the remaining five years, only one out of 35 poles indicates negative accumulation in a given year, corresponding to $2.9 \%$ of missing years. Given the shortness of the record, it is not clear whether the first year was unusual and, if so, how frequently such unusual years occur. Moreover, two of the negative values measured during the first year are within ...imated error limits $(0.5 \mathrm{~cm}$ of snow, based on the tabulated 'pole heights) not significantly different from zero. Further, all four negative values measured during the first year are within the estimated rate of snow settling (2 - 3 cm of firn annually; Gow [1965]) and may be due to vertical compaction of the snow around the poles, rather than zero or negative accumulation. Omitting these four values from the record, the frequency of observed negative accumulation reduces to $2.4 \%$.

An additional complication with the interpretation of the stake record is that the comparative small sample size does not well constrain the percentage of missing years. Again, by calculating Pearson's $\mathrm{C}$ as a function of the probability, $\mathrm{Q}$, of zero or negative accumulation, the range of $Q$ that describes with $95 \%$ confidence the stake measurements can be determined. 
If all nine negative values in the stake measurements are considered indicative of negative net accumulation, the frequency of missing years ranges from 2.3 to $8.0 \%$. If the four negative values measured during the first year are omitted, this range becomes 1.0 to $5.5 \%$. Thus, it could be argued that the pole measurements suggest that as little as $1 \%$ of annual layers may have zero thickness. However, even with this lower limit, use of a gamma distribution indicates that there must be a significant number of horizons missing from the record observed in the core (Figure 2, curve 7).

\section{A Dual-Maximum Distribution?}

A further possibility is that the actual distribution is characterized by two maxima, with the gamma distribution describing most of the layer thicknesses, but with a secondary, smaller and narrow maximum centered around zero layer thickness. Such a distribution could be the result of a process that favors the elimination of layers of intermediate thickness, possibly erosion of thin strata over a hardened surface by wind. The secondary peak would not be stratigraphically detectable if it were sufficiently narrow. More detailed measurements of snow deposition are needed to confirm or disprove the model for a dual-maximum distribution.

\section{Conclusions}

There is a basic incompatibility between the distribution of layer thickness measured in firn cores at South Pole, and estimates of zero-accumulation years from pole-height measurements. The frequency distribution of annual snow layers identified in cores and a snowmine is compatible with a gamma or a log-normal distribution and smoothly approaches zero for zero layer thickness [Giovinetto and Schwerdtfeger, 1966]. A similar distribution was used by McConnell et al. [1997] to describe monthly accumulation at South Pole. However, this distribution does not allow for the significant $(>1 \%$ ) number of zero-accumulation years based on measurements of exposed pole height. The implication is that either a large percentage of years $(\sim 10 \%)$ is missing from the observed record because of unidentified stratigraphic horizons, or that the pole-height data are misinterpreted. A third possibility is that the true frequency distribution is characterized by a dual maximum.

Resolving this discrepancy is important for a correct interpretation of observed stratigraphic records and inferred histories of snow accumulation. With an unknown number of layers missing from the measurements, the long-term accumulation rate cannot be determined reliably, nor can recent changes in snow deposition be detected.
A possible remedy to solve this conundrum is to constrain the long-term average accumulation rate by identifying a known time horizon in the core, for example by recognizing the stratigraphic signature of a known volcanic eruption. A further remedy would be accurate and frequent measurements of snow accumulation. Time series of snow deposition and erosion would be very valuable in developing models that describe the processes affecting the amount of snow added annually at one site.

Acknowledgments. This work was supported by the U.S. National Science Foundation (grant no. OPP-9316509). Byrd Polar Research Center contribution no. C-1113.

\section{References}

Casella, G., and R. L. Berger, Statistical inference, 650 pp., Duxbury Press, Belmont CA, 1990.

Giovinetto, M. B., and W. Schwerdtfeger, Analysis of a 200 year snow accumulation series from the South Pole, Arch. Meteo. Geoph. Bioklim., 15(2A), 227-250, 1966.

Gow, A. J., On the accumulation and seasonal stratification of snow at the South Pole, J. Glac., 5, 467-477, 1965.

Haan, C. T., Statistical methods in hydrology, $378 \mathrm{pp}$., Iowa State University Press, Ames IA,. 1977.

Jouzel, J., L. Merlivat, J. R. Petit and C. Lorius, Climatic information over the last century deduced from a detailed isotopic record in the South Pole snow, J. Geoph. Res., 88, 2693-2703, 1983.

Hogan, A. W., and A. J. Gow, Occurrence frequency of thickness of annual snow accumulation layers at South Pole, J. Geoph. Res., 102, 14,021-14,027, 1997.

Larsen, R. J., and M. L. Marx, An introduction to mathematical statistics and its applications (2nd, ed.), 630 pp., Prentice Hall, Englewood Cliffs NJ, 1986.

McConnell, J. R., R. C. Bales and D. R. Davis, Recent intra-annual snow accumulation at South Pole: implications for ice core interpretation, J. Geoph. Res., 102, 21,947-21,954, 1997.

Mosley-Thompson, E., and L. G. Thompson, Nine centuries of microparticle deposition at the South Pole, Quat. Res., 17, 1-13, 1982.

Mosley-Thompson, E., and six others, Recent increase in South Pole snow accumulation, Ann. Glac., 21, 131-138, 1995.

Thom, H. C. S., A note on the gamma distribution, Mon. Weather Rev., 86, 117-122, 1958.

A. J. Gow, U.S. Army CRREL, 72 Lyme Road, Hanover, NH 03755 (e-mail: tgow@crrel.usace.army.mil).

C. J. van der Veen, Byrd Polar Research Center, The Ohio State University, 1090 Carmack Road, Columbus, OH 43210 (e-mail: vanderveen.1@osu.edu).

I. M. Whillans, Byrd Polar Research Center and Department of Geological Sciences, The Ohio State University, 1090 Carmack Road, Columbus, $\mathrm{OH} 43210$ (e-mail: whillans+@osu.edu).

(Received October 12, 1998; revised November 20, 1998; accepted November 25, 1998). 